\title{
Serum metabolic profiling identified a distinct metabolic signature in patients with idiopathic pulmonary fibrosis - a potential biomarker role for LysoPC
}

Barbara Rindlisbacher $^{1 \dagger}$, Cornelia Schmid ${ }^{2 \dagger}$, Thomas Geiser ${ }^{2}$, Cédric Bovet ${ }^{1 *}$ (1) and Manuela Funke-Chambour ${ }^{2}$

\begin{abstract}
Background: Idiopathic pulmonary fibrosis (IPF) is a lethal lung disease of unknown etiology. Patients present loss of lung function, dyspnea and dry cough. Diagnosis requires compatible radiologic imaging and, in undetermined cases, invasive procedures such as bronchoscopy and surgical lung biopsy. The pathophysiological mechanisms of IPF are not completely understood. Lung injury with abnormal alveolar epithelial repair is thought to be a major cause for activation of profibrotic pathways in IPF. Metabolic signatures might indicate pathological pathways involved in disease development and progression. Reliable serum biomarker would help to improve both diagnostic approach and monitoring of drug effects.
\end{abstract}

Method: The global metabolic profiles measured by ultra high-performance liquid chromatography coupled to high-resolution mass spectrometry (UHPLC-HRMS) of ten stable IPF patients were compared to the ones of ten healthy participants. The results were validated in an additional study of eleven IPF patients and ten healthy controls.

Results: We discovered 10 discriminative metabolic features using multivariate and univariate statistical analysis. Among them, we identified one metabolite at a retention time of 9.59 min that was two times more abundant in the serum of IPF patients compared to healthy participants. Based on its ion pattern, a lysophosphatidylcholine (LysoPC) was proposed. LysoPC is a precursor of lysophosphatidic acid (LPA) - a known mediator for lung fibrosis with its pathway currently being evaluated as new therapeutic drug target for IPF and other fibrotic diseases.

Conclusions: We identified a LysoPC by UHPLC-HRMS as potential biomarker in serum of patients with IPF. Further validation studies in a larger cohort are necessary to determine its role in IPF.

Trial Registration: Serum samples from IPF patients have been obtained within the clinical trial NCT02173145 at baseline and from the idiopathic interstitial pneumonia (IIP) cohort study. The study was approved by the Swiss Ethics Committee, Bern (KEK 002/14 and 246/15 or PB_2016-01524).

Keywords: Idiopathic pulmonary fibrosis, Serum, Ultra high-performance liquid chromatography, High-resolution mass spectrometry, Metabolomics, Lysophosphatidylcholine

\footnotetext{
* Correspondence: cedric.bovet@insel.ch

${ }^{\dagger}$ Equal contributors

${ }^{1}$ University Institute of Clinical Chemistry, Inselspital, Bern University Hospital,

$\mathrm{CH}-3010$ Bern, Switzerland

Full list of author information is available at the end of the article
} 


\section{Background}

Idiopathic pulmonary fibrosis (IPF) is a severe and progressive fibrosing interstitial lung disease with sinister prognosis. The median survival is about 3-5 years after onset of symptoms, although there are various disease progression patterns [1-3]. Patients present with unspecific symptoms and signs, such as dyspnea on exertion, bibasilar inspiratory crackles and non-productive cough $[4,5]$. Males over 60 years with a history of smoking have an increased risk to develop IPF. Still the exact cause remains unknown [6,7]. Abnormal alveolar epithelial wound healing with activation of pro-fibrotic pathways is considered as a major initiating event for IPF [8]. In addition, accumulation of myofibroblasts and production of extracellular matrix leads to scarring of lung tissue with loss of function [9]. Several pro-fibrotic pathways involved in the pathogenesis of IPF have been identified and targeted for drug development [10]. Today, disease-modifying drugs are available, but none of them leads to a cure. Anti-fibrotic treatment mainly slows down disease progression [11].

IPF is diagnosed in a multidisciplinary setting with typical patterns in high resolution computed tomography (HRCT) and, if necessary, invasive methods as bronchoscopy and lung biopsy [1]. The diagnosis is made if typical criteria of usual interstitial pneumonia (UIP) pattern are fulfilled in HRCT and/ or in lung biopsy and other causes of interstitial lung diseases (ILD) have been excluded [1]. Invasive procedures are of risk for respiratory-impaired patients and not always possible. Less invasive methods are urgently needed to facilitate the diagnostic, prognostic and therapeutic monitoring strategies. Blood is easy to obtain without putting the patients at risk. Unfortunately, no serum or plasma biomarkers have been established in clinical routine so far and new biomarker candidates are urgently needed [12].

Nowadays, global metabolic profiling using ultra high-performance liquid chromatography coupled to high-resolution mass spectrometry (UHPLC-HRMS) offers the possibility to discover pathologically regulated molecules. These molecules might give information about aberrant metabolic pathways in a disease. Characteristic metabolites might offer the opportunity to understand pathological processes and to discover new potential diagnostic and/or prognostic biomarkers [13]. To our knowledge, no study investigating the global blood metabolic profile from IPF patients by UHPLC-HRMS is currently available. This approach has been recently used to identify metabotypes of asthma severity [14]. For IPF, proposed biomarkers belong to chemokines (IL-8, CCL18), proteases (MMP-1 and MMP- 7), and growth factors (IGBPs) families [15]. None of these proteins biomarkers has been established in clinical routine. In this study, we aimed to search for different metabolic profiles to identify new possible pathways and potential biomarkers for IPF.

\section{Methods}

Study cohort

For the pilot and validation study, serum samples of patients with stable IPF ( $n=10, n=11$ respectively) and control subjects $(n=10, n=11$ respectively) were obtained from the Department for Pulmonary Medicine, University Hospital, Inselspital, Bern, Switzerland and stored by $-80{ }^{\circ} \mathrm{C}$ until analysis. IPF was diagnosed according to the current international guidelines of 2011 [1]. High resolution chest CT scans of IPF patients were evaluated by a radiologist experienced in ILD diagnosis. If necessary, a histological evaluation including face-toface multidisciplinary discussion with the treating pulmonologists, pathologists and radiologists was done. Clinical baseline characteristics, including smoking habits and lung function, were assessed and documented. Part of the serum samples from IPF patients have been obtained within the clinical trial NCT02173145 at baseline and from the idiopathic interstitial pneumonia (IIP) cohort study. The study protocol was approved by the local Ethics Committee (Swiss Ethics Committee, Bern (KEK 002/14 and 246/15 or PB_2016-01524)) and all participants signed written informed consent to participate.

\section{Sample preparation}

Serum metabolites were extracted with organic solvent for protein precipitation. Frozen serum was gently thawed at $4{ }^{\circ} \mathrm{C}$. $250 \mu \mathrm{L}$ of $-20{ }^{\circ} \mathrm{C}$ cold methanol:acetonitrile $(1: 1, \mathrm{v} / \mathrm{v})$ containing chlorpropamide as internal standard $(1 \mu \mathrm{g} / \mathrm{mL})$ was added to $50 \mu \mathrm{L}$ serum in a $1.5 \mathrm{~mL}$ CapLock tube. Samples were shortly vortexed, stored at $-80{ }^{\circ} \mathrm{C}$ for $30 \mathrm{~min}$ and then centrifuged twice at $14^{\prime} 000 \mathrm{~g}$ for $20 \mathrm{~min}$ at $4{ }^{\circ} \mathrm{C}$. The supernatants were transferred into total recovery liquid chromatography mass spectrometry (LC-MS) vials. In addition to the serum samples, a blank sample was similarly extracted (water collected in a similar CapLock tube used for sample preparation). Pooled group samples were generated by combining $50 \mu \mathrm{L}$ of each samples from the same group. A pooled quality control (QC) sample was generated by mixing $50 \mu \mathrm{L}$ of the pooled group samples. The final serum extracts were stored at $6{ }^{\circ} \mathrm{C}$ until analysis.

\section{UHPLC-HRMS and TWIM-MS analysis}

The serum extracts were analyzed in a randomized block design order on a high resolution mass spectrometer (Synapt G2-S HDMS, Waters, Milford, MA, USA) coupled to a 2D UPLC Acquity I-Class system (Waters, Milford, MA, USA). Two $\mu \mathrm{L}$ of the extracted metabolites 
were separated on a ACQUITY UPLC HSS T3 column $(1.0 \mathrm{~mm} \times 100 \mathrm{~mm}, 1.8 \mu \mathrm{m}$, Waters $)$ at a flow rate of $0.17 \mathrm{~mL} / \mathrm{min}$. The mobile phase was composed of $0.1 \%$ (v/v) formic acid in (A) 1\% (v/v) methanol in $\mathrm{H}_{2} \mathrm{O}$ and (B) methanol. The following $\mathrm{LC}$ gradient was applied: 0 min: $100 \%$ mobile phase A, 1 min: 100\% A, 11 min: $1 \%$ A, 13.0 min: $1 \%$ A, 13.1 min: $100 \%$ A, 15 min: $100 \%$ A. The column temperature was set to $50{ }^{\circ} \mathrm{C}$ and the autosampler to $6{ }^{\circ} \mathrm{C}$. Standard mass spectrometric parameters were $0.5 \mathrm{kV}$ and $20 \mathrm{~V}$ for capillary voltage and cone voltage, respectively. Desolvation and source temperature were kept at $450{ }^{\circ} \mathrm{C}$ and $120{ }^{\circ} \mathrm{C}$, respectively. Cone and desolvation flows were set to $150 \mathrm{~L} / \mathrm{h}$ and $800 \mathrm{~L} / \mathrm{h}$, respectively. Leucine-Enkephalin $([\mathrm{M}+$ $\mathrm{H}]^{+} m / z=556.2766,[\mathrm{M}-\mathrm{H}]^{-} m / z=554.2620$ ) was acquired every $20 \mathrm{~s}$ for lock mass correction. Mass spectra were acquired at a scan time of $0.2 \mathrm{~s}$ in the $\mathrm{MS}^{\mathrm{E}}$ resolution mode between $\mathrm{m} / \mathrm{z} 50$ and 1200. In addition, datadependent acquisition (DDA) MS/MS experiments were performed on the pooled group and QC samples. Before sample analysis, the system was equilibrated by injecting 10 times the QC sample and the QC sample was then analyzed after every fifth sample injection. A system suitability test (SST) containing standards was measured at the beginning and the end of the analytical run to ensure retention time stability, intensity stability and mass error $\leq 8 \mathrm{ppm}$. The instrument was controlled via MassLynx (version 4.1, Waters). The pilot study set was analyzed with one replicate per IPF patient and healthy control sample, whereas for the validation set, duplicate analysis was applied.

To improve structural elucidation of the regulated metabolites, traveling wave ion mobility mass spectrometry (TWIM-MS) of extracted serum was additionally performed. Extracted serum was separated under the same chromatographic conditions described above. Mass spectra were acquired in the positive and negative ionization mode at a scan time of $0.5 \mathrm{~s}$ in the HDMS $^{\mathrm{E}}$ resolution mode between $\mathrm{m} / z 50$ and 1200. The TWIM wave height was set at $40 \mathrm{~V}$ and the wave velocity was ramped from 1000 to $300 \mathrm{~m} / \mathrm{s}$. Precursors were fragmented after the TWIM separation in the transfer T-cell set and transferred to the TOF at a velocity of $220 \mathrm{~m} / \mathrm{s}$. The ion mobility was calibrated with poly-DL-alanine, which allowed the determination of the collision cross section (CCS) in nitrogen [16]. A lipid standard mixture of phosphatidylcholines (PC(18:0/0:0), PC(18:2/0:0), PC(12:0/12:0), $\mathrm{PC}(14: 0 / 14: 0), \quad \mathrm{PC}(18: 1 / 18: 1), \quad \mathrm{PC}(16: 0 / 0: 0)$ obtained from Echelon Biosciences) was prepared in acetonitrile:isopropanol:water $(2: 1: 1, \mathrm{v} / \mathrm{v})$ and used as quality control for the CCS measurements. Two $\mu \mathrm{L}$ of this lipid standard mixture at 0.1 and $1.0 \mu \mathrm{g} / \mathrm{mL}$ were analyzed by UHPLC-TWIM-MS in the positive and negative ESI mode, respectively. Data processing was performed using UNIFI (version 1.8.2.169, Waters, Millford, USA).

\section{Data processing and statistical analysis}

After lock-mass correction and chromatographic alignment with Progenesis QI (version 2.2, Nonlinear Dynamics, Newcastle, UK), ion patterns were deconvoluted between $0.45-11.5 \mathrm{~min}$. As possible ions, $[\mathrm{M}+\mathrm{H}]^{+},[\mathrm{M}+$ $\mathrm{Na}]^{+},[\mathrm{M}+\mathrm{K}]^{+},\left[\mathrm{M}+\mathrm{H}-\mathrm{H}_{2} \mathrm{O}\right]^{+},\left[\mathrm{M}+\mathrm{H}-2 \mathrm{H}_{2} \mathrm{O}\right]^{+},[\mathrm{M}+2 \mathrm{H}]^{2}$ ${ }^{+},[\mathrm{M}+3 \mathrm{H}]^{3+},\left[2 \mathrm{M}+\mathrm{H}^{+},[2 \mathrm{M}+\mathrm{Na}]^{+}\right.$and $[2 \mathrm{M}+\mathrm{K}]^{+}$were defined in the positive ion mode, $[\mathrm{M}-\mathrm{H}]^{-},\left[\mathrm{M}-\mathrm{H}-\mathrm{H}_{2} \mathrm{O}\right]^{-}$, $[\mathrm{M}+\mathrm{HCOOH}-\mathrm{H}]^{-},[\mathrm{M}-2 \mathrm{H}]^{2-},[\mathrm{M}-3 \mathrm{H}]^{3-}$ and $[2 \mathrm{M}-\mathrm{H}]^{-}$in the negative ion mode. The abundances of the features were normalized to all compounds. Features eluting between $0.5-10.5 \mathrm{~min}$ with a chromatographic peak width $\geq$ $0.05 \mathrm{~min}$, having a coefficient of variation of the peak area $\leq 30 \%$ in the QC samples, singly charged ions and ions having a maximum abundance across all samples $\geq 200$ (positive mode, arbitrary threshold) or $\geq 150$ (negative mode, arbitrary threshold), were selected for further evaluation. In addition, the metabolic features having an abundance in blank higher than in QC and which were at least twice more abundant in blank were excluded. Known drug/drug metabolites taken from patient were also excluded from the dataset.

The normalized abundances of each filtered metabolic features were subjected to multivariate and univariate statistical analysis. For the validation set, the features abundances of the duplicate analysis were averaged. For multivariate statistical analysis, data were subjected to $\mathrm{Pa}-$ reto scaling prior to orthogonal projections of latent structures discriminant analysis (OPLS-DA) with SIMCA (version 14, Umetrics, Umeå, Sweden). Results were further integrated if the $\mathrm{n}$-fold ( $\mathrm{n}=$ total number of sample, leaveone-out cross validation approach) cross-validated correlation $\mathrm{Q}^{2}$ (cum) was $\geq 0.5$, if the cross validatory ANOVA $p$-value was $\leq 0.05$ and if the permutation test was passed (20 permutations, $\mathrm{R}^{2}>\mathrm{R}_{\text {permutation }}^{2}$ and $\mathrm{Q}_{\text {permutation }}^{2}<0$ ). Discriminative features were selected based on a VIP PRED score $\geq 1.5$ and absolute $\mathrm{p}$ (corr) $\geq$ 0.5. The confidence interval of the selected features was also not including 0 . With this approach, only metabolic features with strong model contribution and high reliability were selected. Univariate statistical analysis was performed to consistently evaluate the filtered metabolic features and to screen for additional metabolites. For the pilot study, univariate analysis of variance (ANOVA) was based on arcsinh transformed data from Progenesis QI. For the validation study, ANOVA was performed with SIMCA and was based on $\log 2$ transformed and Pareto scaled normalized abundances. The false discovery rate (FDR) due to 
multiple testing was estimated according to Benjamini Hochberg [17]. FDR corrected $p$-values (i.e. q-value) threshold was set at $\mathrm{q} \leq 0.05$.

Structure and formula of the isolated discriminative metabolic features were searched against the Human Metabolome Database (HMDB, version 3.6) and LIPID MAPS Structure Database (LMSD, version from December 6,2016$)$ with a mass accuracy of $8 \mathrm{ppm}$. Metabolic features with only one adduct ion were assumed to be $[\mathrm{M}+\mathrm{H}]^{+}$and $[\mathrm{M}-\mathrm{H}]^{-}$ions in the positive and negative ionization mode, respectively.

\section{Results}

\section{Study cohort}

In the pilot study, 10 IPF patients and 10 age- and sexmatched healthy controls were included. The mean age of IPF patients and of healthy controls was 67.8 respectively 68.7 years. Ninety percent of all participants were male in both groups. Lung functional measurements showed a reduced median forced vital capacity (FVC) of 2.4 $\mathrm{L}$ (mean $65 \%$ predicted) in IPF patients and a median FVC of $4.1 \mathrm{~L}$ (mean 115\% predicted) in controls. Average 3-year mortality prediction in IPF patients was in $42.1 \%$ according to the currently used GAP staging method (stage II) [2]. Eighty percent of IPF patients and controls had a history of cigarette smoking.

For the validation study, blood sampling from 7 IPF patients was performed 2 weeks after the initial pilot study. Four recently diagnosed IPF patients and all healthy controls were newly collected for the validation study. One sample of the control group was excluded due to analytical problems during sample preparation. Eleven IPF patients and 10 healthy controls remained for further analysis. The baseline characteristics of patients and controls of both pilot and validation study are summarized in Table 1.

\section{Metabolic serum profiling by UHPLC-HRMS}

The differentially regulated serum metabolites in healthy participants and IPF patients were searched for by nontargeted metabolic profiling using UHPLC-HRMS. The flowchart for sample preparation and analysis is illustrated in Fig. 1. After data processing and filtration, 2426 and 1740 metabolic features were detected in the pilot study by UHPLC-HRMS in the positive and negative electrospray ionization (ESI) mode, respectively. Principal component analysis (PCA) of the non-targeted metabolic profiles measured by UHPLC-HRMS suggested differences between healthy controls and IPF patients (Fig. 2). In the negative ESI mode, one IPF sample was defined as outlier and excluded from further statistical analysis, otherwise multivariate and univariate statistical analysis of the data did not isolate differentially regulated metabolic features (data not shown). Acceptable OPLSDA model characteristics were obtained (Table 2) and based on the selection criteria, 67 and 103 discriminative

Table 1 Baseline characteristics of healthy controls and IPF patients

\begin{tabular}{|c|c|c|c|c|}
\hline & \multicolumn{2}{|l|}{ Pilot study } & \multicolumn{2}{|c|}{ Validation study } \\
\hline & Healthy & IPF & Healthy & IPF \\
\hline Subjects (male \%) & $10(90)$ & $10(90)$ & $10(60)$ & $11(82)$ \\
\hline Age (years) & $68.7 \pm 7.9$ & $67.8 \pm 8.6$ & $32.4 \pm 15.3$ & $66.1 \pm 8.6$ \\
\hline BMl kg/m² & $28.9 \pm 5.1$ & $26.9 \pm 3.6$ & $22.6 \pm 2.7$ & $26.3 \pm 4.3$ \\
\hline $\mathrm{BMI} \geq 25 \mathrm{~kg} / \mathrm{m}^{2}$ & 7 & 5 & 2 & 6 \\
\hline Diabetes mellitus type 2 (n) & 1 & 2 & 0 & 3 \\
\hline Hypertension & 5 & 5 & 0 & 3 \\
\hline \multicolumn{5}{|l|}{ Lung function } \\
\hline FVC, L & $4.1 \pm 0.4$ & $2.4 \pm 0.5$ & $4.5 \pm 1.0$ & $2.4 \pm 0.6$ \\
\hline FVC (\% predicted) & $114.6 \pm 8.5$ & $65.1 \pm 11.3$ & $94.0 \pm 10.3$ & $63.1 \pm 14.3$ \\
\hline DLCO (\% predicted) & $129.6 \pm 31.1$ & $43 \pm 15.0$ & $87.8 \pm 11.3$ & $44.6 \pm 14.6$ \\
\hline GAP Stage (I-III) & - & $|-| \mid$ & - & $\mid-\|$ \\
\hline \multicolumn{5}{|l|}{ Smoking status } \\
\hline Current Smokers $n$ (median pack years \pm SD) & 0 & 0 & $5(8.2 \pm 14.5)$ & 0 \\
\hline Former Smokers $n$ (median pack years \pm SD) & $8(5.5 \pm 5.7)$ & $8(25.4 \pm 15.2)$ & 0 & $8(13.9 \pm 13.3)$ \\
\hline \multicolumn{5}{|l|}{ Antifibrotic therapy } \\
\hline Pirfenidone n (\%) & - & $6(60)$ & - & $6(54.5)$ \\
\hline Nintedanib n (\%) & - & $3(30)$ & - & $4(36.4)$ \\
\hline No antifibrotics n (\%) & - & $1(10)$ & - & $1(9.1)$ \\
\hline
\end{tabular}

FVC Forced vital capacity, DLCO Diffusing capacity of the lung for carbon monoxide, BMI Body Mass Index 


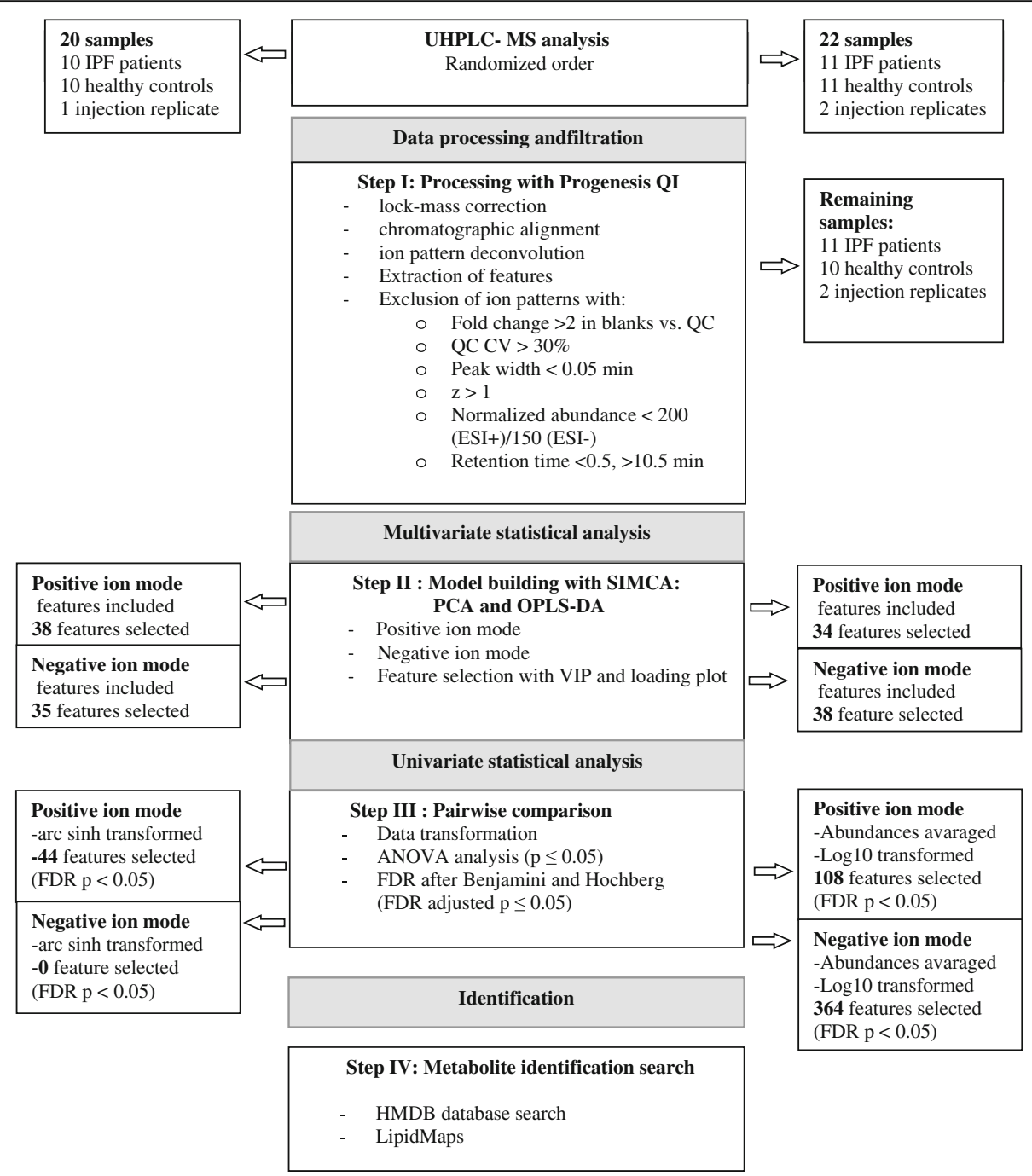

Fig. 1 Flowchart for sample measurement, data processing and statistical analysis. [60]

features were selected by univariate and/or multivariate analysis in the positive and negative ESI mode, respectively (data not shown).

To validate our results, a new set of samples was profiled by UHPLC-HRMS. After data processing and filtration, 1229 and 1059 metabolic features were detected by UHPLC-HRMS in the positive and negative ESI mode, respectively. Based on the PCA score plots (data not shown), one healthy participant was considered as outlier and was further excluded from statistical analysis. The PCA score plots obtained after data filtration and exclusion of this participant are shown in Fig. 3. Similar to the pilot study, satisfactory multivariate model parameters were obtained in both ionization modes (Table 2). Based on our selection criteria, 103 and 364 discriminative features were selected by univariate and/or multivariate analysis in the positive and negative ESI mode, respectively (data not shown).
To identify common metabolic features regulated between healthy participants and IPF patients in the pilot and validation study, the retention time and $\mathrm{m} / \mathrm{z}$ ratio of the discriminative metabolic features isolated in each study by multivariate and/or univariate analysis were compared. Among them, 3 and 27 metabolic features were commonly found in the positive and negative ionization mode, respectively. Based on their abundance profile (Additional file 1: Figure S1), we hypothesized that the metabolic features mainly detected in the IPF samples were related to drugs and/or drug metabolites. After exclusion of these features, 10 metabolic features remained differentially regulated in the pilot and were confirmed in the validation study. Their corresponding fold changes in abundance and potential annotations found against the metabolite databases are summarized in Table 3.

The identity of inosine was confirmed by comparing the retention times and fragmentation patterns obtained 


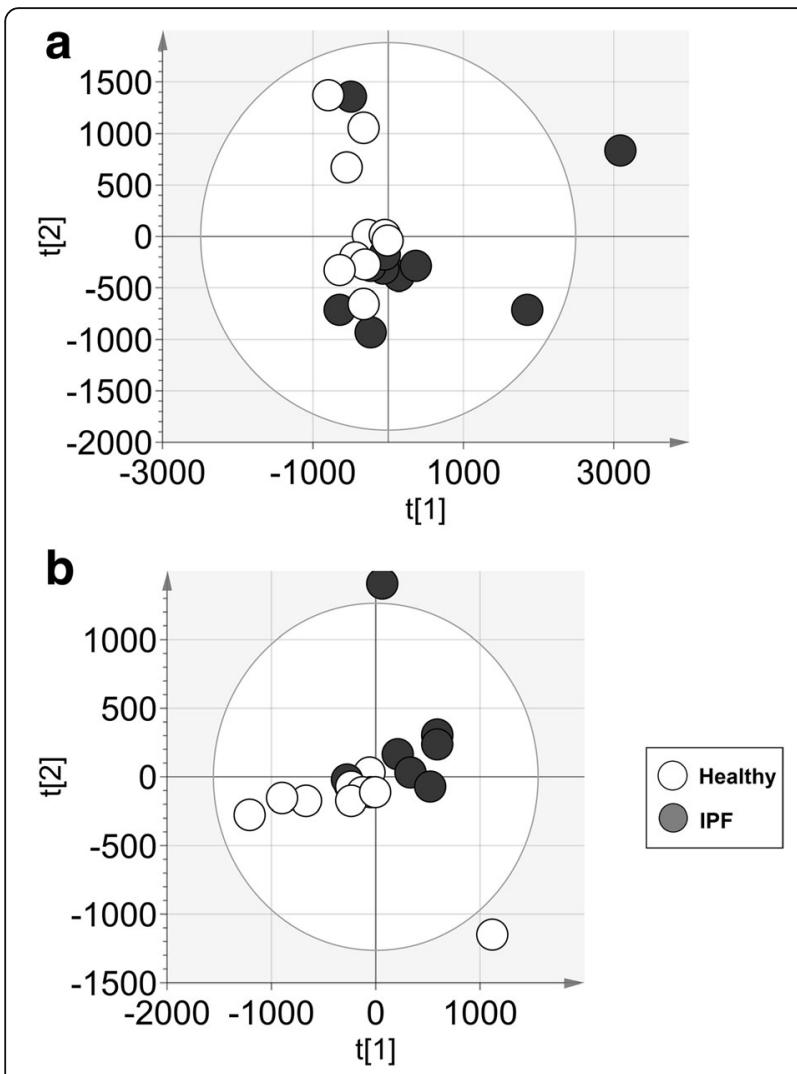

Fig. 2 PCA score plots of the healthy participants and IPF patients of the pilot study measured in the (a) positive and (b) negative ESI mode

in serum to an authentic inosine standard. This purine metabolite was upregulated in the pilot study and downregulated in the validation study. Only three metabolic features eluting at $5.94 \mathrm{~min}(m / z=332.242)$ and $9.59 \mathrm{~min}(\mathrm{~m} / z=512.334$ in the positive ESI mode and $m / z=556.325$ in the negative ESI mode) were significantly upregulated in IPF patients in both studies.

The metabolic features eluting at 5.94 min was potentially assigned against the HMDB database to 3hydroxydecanoyl carnitine (chemical formula $\mathrm{C}_{17} \mathrm{H}_{33} \mathrm{NO}_{5}$, mass error - $2.7 \mathrm{ppm}$, isotope similarity 96\%). The detection of the characteristic acylcarnitine fragment $\left[\mathrm{C}_{4} \mathrm{H}_{5} \mathrm{O}_{2}\right]^{+}$at $\mathrm{m} / z$ 85.0284 was confirmed by UHPLC-
TWIM-MS measurement (mass error-4.8 ppm, Additional file 2: Figure S2). No significant differences were found in the global acylcarnitine profile (data not shown, profile extracted as in Bally et al. [18]).

At $9.59 \mathrm{~min}$, three discriminative metabolic features were two times more abundant in the serum of IPF patients compared to healthy participants (Table 3, $m / z=512.334$ in the positive ESI mode, $m / z=556.325$ and 496.303 in the negative ESI mode, with the latter being significant only in one study). Presumably, these co-eluting ions belonged to the same metabolic features. In the negative ESI mode, the detected ion pattern agreed with a phosphatidylcholine (PC) or sphingomyelin $\left[\mathrm{M}-\mathrm{CH}_{3}\right]^{-}$and $[\mathrm{M}+\mathrm{CHOO}]^{-}$ions. These ion patterns were confirmed by the analysis of PC lipid standards (data not shown) and agreed with the literature $[19,20]$. The MS/MS spectra acquired in the positive and negative ESI mode (DDA experiments, Additional file 3: Figure S3) further suggested the detection of a LysoPC with the chemical formula $\mathrm{C}_{24} \mathrm{H}_{50} \mathrm{NO}_{8} \mathrm{P}$ (mass error $-1.0 \mathrm{ppm}$, isotope similarity 98\%). No LysoPC structure matching the MS data was found against the LIPID MAPS database and the literature. Therefore, we assumed a LysoPC structure with an ether or hydroxylated acyl chain in the sn-1 or sn-2 position (Scheme 1). We further characterized this unknown LysoPC with TWIM-MS and measured a CCS of $227.5 \AA^{2}$ for the protonated ion (Table 4). Excellent CCS agreements with the literature (Table 4, CCS error $<1.1 \%$ ) were obtained for the PC standard mixture confirming the excellent inter-laboratory reproducibility of CCS values [16]. A single TWIM peak was detected for the unknown LysoPC, which suggested the detection of a single LysoPC having a compacter conformation than $\mathrm{PC}(16: 0 / 0: 0)$. To our knowledge, the influence of ether or hydroxylated acyl chain on the LysoPC CCS has not been reported. It is therefore difficult to hypothesize the most probable structure for this unknown LysoPC based on the TWIM-MS measurement. The abundance profiles of all significantly upregulated metabolic features detected in the pilot and validation study (3-

Table 2 Characteristics of the OPLS-DA models for the pilot and validation study sets analyzed in positive (ESI+) and negative (ESI-) ESI mode

\begin{tabular}{|c|c|c|c|c|c|c|}
\hline Study & Ionisation & Number of samples & $R^{2}$ (cum) & $Q^{2}$ (cum) & CV ANOVA p-value & Permutation test \\
\hline Pilot & ESI+ & 20 & 0.894 & 0.599 & 0.0058 & $\begin{array}{l}R^{2}=0.734 \\
Q^{2}=-0.209\end{array}$ \\
\hline Validation & ESI+ & 21 & 0.903 & 0.742 & 0.00014 & $\begin{array}{l}R^{2}=0.694 \\
Q^{2}=-0.318\end{array}$ \\
\hline Pilot & ESI- & 19 & 0.872 & 0.503 & 0.0339 & $\begin{array}{l}R^{2}=0.767 \\
Q^{2}=-0.299\end{array}$ \\
\hline Validation & ESI- & 21 & 0.878 & 0.721 & 0.0003 & $\begin{array}{l}\mathrm{R}^{2}=0.66 \\
\mathrm{Q}^{2}=-0.447\end{array}$ \\
\hline
\end{tabular}




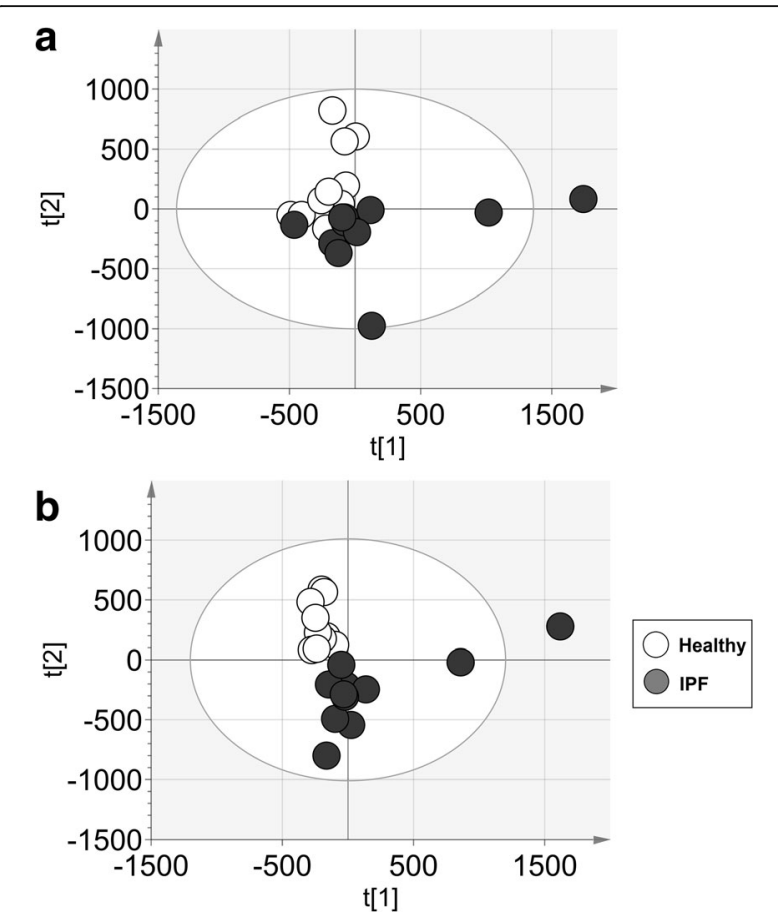

Fig. 3 PCA score plots of the healthy participants and IPF patients of the validation study measured in the (a) positive and (b) negative ESI mode hydroxydecanoyl carnitine, and 2 metabolic features of LysoPC) are shown in Fig. 4.

\section{Discussion}

After excluding potential drugs and drug metabolites, ten metabolic features were isolated in serum from IPF patients by non-targeted UHPLC-HRMS based metabolomics. Among them, 3 metabolic features were significantly upregulated in IPF patients in both, pilot and validation study. Based on the MS data and the databases, we hypothesized the detection of 3-hydroxydecanoyl carnitine and a LysoPC, the second as a potential precursor for lysophosphatidic acid (LPA) [21].

Identification of differences between IPF and healthy individuals by biomarker is important for diagnosis and prognosis and supports the clinician for evaluation of individual treatment responses. In addition, heterogeneity of disease course suggests different pathophysiological phenotypes in IPF. A recent study identified molecules of the autotaxin-lysoPA pathway by metabolomics analysis equally for patients with COPD [22]. In this study, lung functional parameters in males were associated with LPA subspecies levels in COPD [22]. Due to the predominant male patients and small number of participants we are unable to further investigate a gender association in our study.

In the positive ESI mode, we detected a metabolic feature $(\mathrm{m} / \mathrm{z} 332.242$ at a retention time of $5.94 \mathrm{~min})$ with possible identification of 3-hydroxydecanoyl carnitine, a

Table 3 LC-MS characteristics (retention time, $\mathrm{m} / \mathrm{z}$ ratio) and fold changes of the metabolic features isolated by multivariate and/or univariate analysis (FDR $\leq 0.05)$ in the pilot and validation study

\begin{tabular}{|c|c|c|c|c|c|c|c|c|}
\hline Study & Compound ID & Potential ID [adduct] & Ionisation & $m / z$ & $\begin{array}{l}\text { RT } \\
(\min )\end{array}$ & $\begin{array}{l}\text { Fold change IPF/ } \\
\text { Healthy }\end{array}$ & $\begin{array}{l}\text { FDR } \\
\text { (Univariate) }\end{array}$ & Multivariate \\
\hline $\begin{array}{l}\text { Pilot } \\
\text { Validation }\end{array}$ & $\begin{array}{l}5.94 \_332.2423 \mathrm{~m} / \mathrm{z} \\
5.94 \_332.2419 \mathrm{~m} / \mathrm{z}\end{array}$ & $\begin{array}{l}\text { 3-hydroxydecanoyl } \\
\text { carnitine }[\mathrm{M}+\mathrm{H}]^{+}\end{array}$ & ESI+ & $\begin{array}{l}332.2423 \\
332.2419\end{array}$ & $\begin{array}{l}5.94 \\
5.94\end{array}$ & $\begin{array}{l}4.0 \\
25.9\end{array}$ & $\begin{array}{l}0.047 \\
0.003\end{array}$ & $\begin{array}{l}\text { no } \\
\text { no }\end{array}$ \\
\hline $\begin{array}{l}\text { Pilot } \\
\text { Validation }\end{array}$ & $\begin{array}{l}9.59 \_511.3269 n \\
9.59 \_511.3259 n\end{array}$ & $\begin{array}{l}\text { LysoPC } \\
{[\mathrm{M}+\mathrm{H}]^{+},[\mathrm{M}+\mathrm{Na}]^{+},} \\
{[\mathrm{M}+\mathrm{K}]^{+}}\end{array}$ & ESI+ & $\begin{array}{l}512.3342 \\
512.3332\end{array}$ & $\begin{array}{l}9.59 \\
9.59\end{array}$ & $\begin{array}{l}1.9 \\
1.9\end{array}$ & $\begin{array}{l}0.037 \\
0.008\end{array}$ & $\begin{array}{l}\text { yes } \\
\text { yes }\end{array}$ \\
\hline $\begin{array}{l}\text { Pilot } \\
\text { Validation }\end{array}$ & $\begin{array}{l}9.59 \_496.3026 \mathrm{~m} / \mathrm{z} \\
9.58 \_496.3029 \mathrm{~m} / \mathrm{z}\end{array}$ & $\begin{array}{l}\text { LysoPC } \\
{\left[\mathrm{M}-\mathrm{CH}_{3}\right]^{-}}\end{array}$ & ESI- & $\begin{array}{l}496.3026 \\
496.3029\end{array}$ & $\begin{array}{l}9.59 \\
9.59\end{array}$ & $\begin{array}{l}1.6 \\
2.0\end{array}$ & $\begin{array}{l}0.11 \\
4.8710^{-4}\end{array}$ & $\begin{array}{l}\text { yes } \\
\text { yes }\end{array}$ \\
\hline $\begin{array}{l}\text { Pilot } \\
\text { Validation }\end{array}$ & $\begin{array}{l}9.59 \_556.3248 \mathrm{~m} / \mathrm{z} \\
9.59 \_556.3245 \mathrm{~m} / \mathrm{z}\end{array}$ & $\begin{array}{l}\text { LysoPC } \\
{[\mathrm{M}+\mathrm{CHOO}]^{-}}\end{array}$ & ESI- & $\begin{array}{l}556.3248 \\
556.3245\end{array}$ & $\begin{array}{l}9.59 \\
9.59\end{array}$ & $\begin{array}{l}1.9 \\
2.1\end{array}$ & $\begin{array}{l}0.048 \\
5.1910^{-4}\end{array}$ & $\begin{array}{l}\text { yes } \\
\text { yes }\end{array}$ \\
\hline $\begin{array}{l}\text { Pilot } \\
\text { Validation }\end{array}$ & $\begin{array}{l}2.43 \_267.0728 \mathrm{~m} / \mathrm{z} \\
2.38 \_267.0737 \mathrm{~m} / \mathrm{z}\end{array}$ & $\begin{array}{l}\text { Inosine } \\
{[\mathrm{M}-\mathrm{H}]^{-}}\end{array}$ & ESI- & $\begin{array}{l}267.0728 \\
267.0737\end{array}$ & $\begin{array}{l}2.43 \\
2.38\end{array}$ & $\begin{array}{l}1.8 \\
0.7\end{array}$ & $\begin{array}{l}0.22 \\
0.044\end{array}$ & $\begin{array}{l}\text { yes } \\
\text { yes }\end{array}$ \\
\hline $\begin{array}{l}\text { Pilot } \\
\text { Validation }\end{array}$ & $\begin{array}{l}\text { 8.77_370.1807n } \\
8.38 \_369.1738 \mathrm{~m} / \mathrm{z}\end{array}$ & $\begin{array}{l}\text { Androsterone } \\
\text { sulfate }[\mathrm{M}-\mathrm{H}]^{-}\end{array}$ & ESI- & $\begin{array}{l}369.1734 \\
369.1738\end{array}$ & $\begin{array}{l}8.77 \\
8.38\end{array}$ & $\begin{array}{l}0.4 \\
0.3\end{array}$ & $\begin{array}{l}0.22 \\
0.03\end{array}$ & $\begin{array}{l}\text { yes } \\
\text { yes }\end{array}$ \\
\hline $\begin{array}{l}\text { Pilot } \\
\text { Validation }\end{array}$ & $\begin{array}{l}0.88 \_195.8107 \mathrm{~m} / \mathrm{z} \\
0.65 \_195.8115 \mathrm{~m} / \mathrm{z}\end{array}$ & & ESI- & $\begin{array}{l}195.8107 \\
195.8115\end{array}$ & $\begin{array}{l}0.88 \\
0.65\end{array}$ & $\begin{array}{l}0.8 \\
0.9\end{array}$ & $\begin{array}{l}0.25 \\
0.02\end{array}$ & $\begin{array}{l}\text { yes } \\
\text { yes }\end{array}$ \\
\hline $\begin{array}{l}\text { Pilot } \\
\text { Validation }\end{array}$ & $\begin{array}{l}0.88 \_197.8076 \mathrm{~m} / \mathrm{z} \\
0.65 \_197.8090 \mathrm{~m} / \mathrm{z}\end{array}$ & & ESI- & $\begin{array}{l}197.8076 \\
197.8090\end{array}$ & $\begin{array}{l}0.88 \\
0.65\end{array}$ & $\begin{array}{l}0.8 \\
0.9\end{array}$ & $\begin{array}{l}0.23 \\
0.02\end{array}$ & $\begin{array}{l}\text { yes } \\
\text { yes }\end{array}$ \\
\hline $\begin{array}{l}\text { Pilot } \\
\text { Validation }\end{array}$ & $\begin{array}{l}0.88 \_199.8045 \mathrm{~m} / \mathrm{z} \\
0.65 \_199.8057 \mathrm{~m} / \mathrm{z}\end{array}$ & & ESI- & $\begin{array}{l}199.8045 \\
199.8057\end{array}$ & $\begin{array}{l}0.88 \\
0.65\end{array}$ & $\begin{array}{l}0.8 \\
0.9\end{array}$ & $\begin{array}{l}0.24 \\
0.03\end{array}$ & $\begin{array}{l}\text { yes } \\
\text { yes }\end{array}$ \\
\hline $\begin{array}{l}\text { Pilot } \\
\text { Validation }\end{array}$ & $\begin{array}{l}8.57 \_371.1879 \mathrm{~m} / \mathrm{z} \\
8.57 \_371.1879 \mathrm{~m} / \mathrm{z}\end{array}$ & & ESI- & $\begin{array}{l}371.1879 \\
371.1889\end{array}$ & $\begin{array}{l}8.57 \\
8.60\end{array}$ & $\begin{array}{l}0.3 \\
0.2\end{array}$ & $\begin{array}{l}0.24 \\
0.04\end{array}$ & $\begin{array}{l}\text { yes } \\
\text { no }\end{array}$ \\
\hline
\end{tabular}




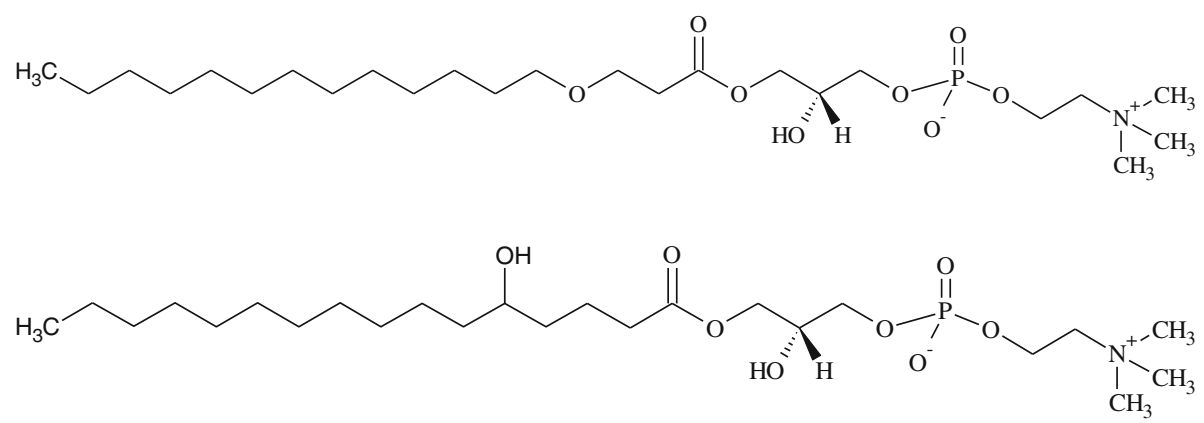

Scheme 1 Potential structures of the LysoPC which was elevated in serum of IPF patients compared to controls. For simplification, only the sn-1 isomers are represented

medium-chain acylcarnitine, which was upregulated in serum of IPF patients (pilot FC 4.0, validation FC 25.9). We did not detect sufficient hydroxycarnitines species to further evaluate their profile because of the insufficient sensitivity of our method. In addition, no significant differences were found in the global acylcarnitine profile. In contrast, medium-chain acylcarnitines were decreased in lung tissue from IPF patients in a recent metabolomics study [23]. According to the authors this may be due to an impaired transport of fatty acids into the mitochondria [23].

A metabolic profiling study using gas-chromatography coupled to mass spectrometry of IPF lung tissue showed that the purine metabolites inosine and hypoxanthine were increased compared to normal lung tissue [24]. Inosine is the precursor for adenosine. In experimental models, adenosine levels have been associated with disease progression for lung fibrosis and could be abrogated by adenosine inhibitor dipyridamole [25]. Extracellular adenosine levels are associated with the progression and exacerbation of pulmonary fibrosis [25]. In addition, adenosine receptors were increased in lungs form IPF patients [26]. Purinergic signaling and scarring of fibrotic tissue have been largely associated [27]. Interestingly, in our study, we found a discordant regulation of inosine between the pilot and the validation set. While in the age-matched pilot study serum levels of inosine were increased in IPF patients, the validation study showed an opposing result. A possible explanation is the lack of age-matched validation cohort. Age-dependent serum adenosine deaminase activity may have had an impact on this result [28].

In our study, we consistently identified a LysoPC in serum from IPF patients. LysoPC is a precursor of LPA, which is a bioactive glycerophospholipid. There are multiple LPA types differing in length and degree of saturation of the fatty acid [29]. LPA is involved in various processes as fibrosis, systemic sclerosis, cancer, inflammation, atherosclerosis, obesity, asthma, multiple sclerosis, neuropathic pain or embryonal implantation [3039]. LPA induces fibrosis in the lung, kidney and liver by epithelial cell death, vascular leakage and fibroblast migration and proliferation [30, 40-42].

The wide range of biological effects can be explained by multiple LPA receptors. LPA mediates its responses via at least six LPA receptors [21]. Pro-fibrotic effects are induced by activation of the specific LPA receptor $\mathrm{LPA}_{1}$ [21]. Both genetic suppression of LPA-receptor 1 and antagonism of the enzyme autotaxin prevent pulmonary fibrosis [42-44]. $\mathrm{LPA}_{1}$-deficient mice did not develop pulmonary fibrosis after bleomycin injury [42]. Additionally, LPA via $\mathrm{LPA}_{2}$ induces $\alpha v \beta 6$ integrinmediated transforming growth factor- $\beta$ (TGF- $\beta$ ) activation in bronchial epithelial cells [45]. It was shown in

Table 4 CCS values obtained from the ion mobility measurements of the lipid standards and the unknown LysoPC. Results shown are averages from three sample analysis

\begin{tabular}{|c|c|c|c|c|c|c|}
\hline Component $[\mathrm{M}+\mathrm{H}]+$ & Formula & Average RT (min) & Average CCS $\left(\AA^{2}\right)$ & RSD CCS (\%) & Literature CCS $\left(\AA^{2}\right)$ & CCS error (\%) \\
\hline Unknown LysoPC & C24H50NO8P & 9.55 & 227.5 & 0.0 & & \\
\hline$P C(16: 0 / 0: 0)$ & C24H50NO7P & 11.01 & 237.9 & 0.2 & $236[16]$ & 0.8 \\
\hline$P C(18: 2 / 0: 0)$ & C26H50NO7P & 10.83 & 234.7 & 0.1 & & \\
\hline$P C(18: 0 / 0: 0)$ & C26H54NO7P & 11.46 & 245.2 & 0.1 & $246[16]$ & 1.1 \\
\hline$P C(12: 0 / 12: 0)$ & C32H64NO8P & 11.96 & 269.4 & 0.1 & $272.4[19]$ & -1.1 \\
\hline$P C(14: 0 / 14: 0)$ & $\mathrm{C} 36 \mathrm{H} 72 \mathrm{NO} 8 \mathrm{P}$ & 12.52 & 281.9 & 0.2 & 282.9 [19] & -0.4 \\
\hline$P C(18: 1 / 18: 1)$ & C44H84NO8P & 13.38 & 300.6 & 0.2 & & \\
\hline
\end{tabular}

CCS Collision cross section 

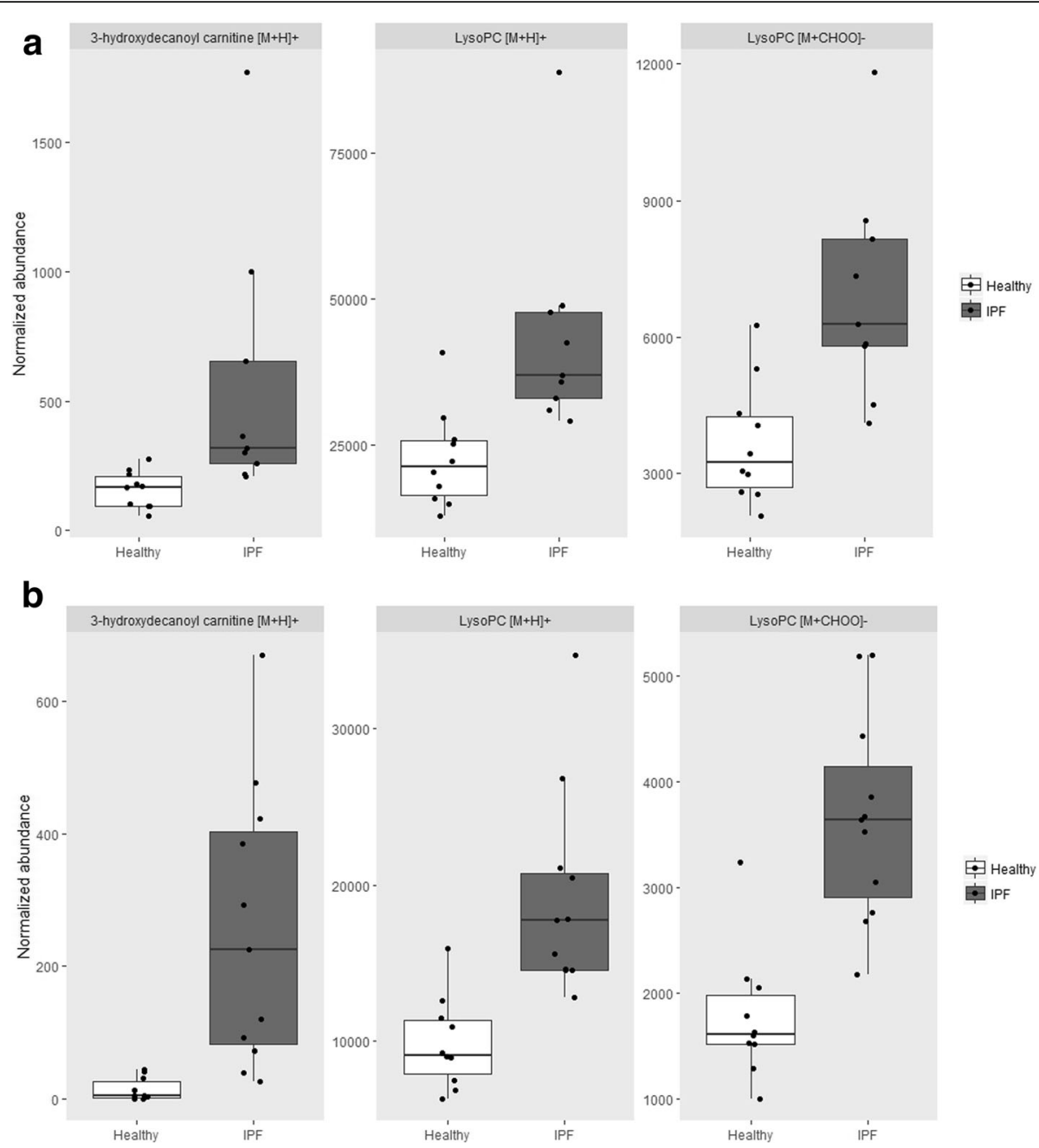

Fig. 4 Normalized abundances of the common significantly regulated metabolic features detected in the (a) pilot study and (b) validation study. The metabolic feature eluting at 5.94 min was assigned to 3-hydroxydecanoyl carnitine $\left(\left[\mathrm{M}+\mathrm{H}^{+}, \mathrm{m} / \mathrm{z}=332.242\right)\right.$, the ones eluting at 9.59 min to the LysoPC (neutral mass $511.327 \mathrm{amu}$, and $[\mathrm{M}+\mathrm{CHOO}]^{-}$at $\mathrm{m} / \mathrm{z}=556.325$ )

another study, that $\mathrm{LPA}_{2}$ knockout mice did not develop pulmonary fibrosis after bleomycin application. Moreover, the expression of TGF- $\beta$ in human lung fibroblasts was inhibited [46].

The source of LPA is unclear. There are at least two different sources of LPA production. One is the hydrolysis of phosphatidic acids, which are located in cell membranes, by phospholipase A1 and A2. But the majority of LPA is produced by the enzymatic cleavage of LysoPC and lysophosphatidylserine by lysophospholipase D activity of the enzyme autotaxin (ATX) [47-49]. In IPF, epithelial cell injury, specifically of type 2 alveolar epithelial cells, is thought to initiate the fibrotic process [9]. After lung injury, dipalmitoylphosphatidylcholine (DPPC), as major surfactant lipid component, is degraded to LysoPC by phospholipase A2 activity by type 2 alveolar epithelial cells [50]. As explained above, LysoPC is a precursor of LPA and converted by the enzyme autotaxin (ATX) [21]. LPA via $\mathrm{LPA}_{1}$ promotes epithelial cell apoptosis after lung injury [51]. But also platelet activation can lead to LPA via autotaxin [52]. In IPF a prothrombotic state is recognized and platelet activation is increased compared to controls [53]. Increased platelet activation might contribute to elevated LPA levels in IPF. Previous studies showed increased level of LPA in the bronchoalveolar lavage fluid and exhaled breath condensate of IPF patients [42,54].

In addition, COPD metabolomics studies also revealed alteration of LPA pathway [22]. LPA pathway has been associated with several different lung disease including hyperoxic lung injury and asthma $[36,55,56]$. As therapeutic approach to interrupt the LysoPC - LPA axis, an oral inhibitor of autotaxin (GLPG1690) is currently evaluated in a Phase 2 study for IPF patients $[57,58]$. If the production of LPA is reduced by inhibition of autotaxin, both $\mathrm{LPA}_{1}$ and $\mathrm{LPA}_{2}$ pathways would be targeted [58]. In our study, LPA was not detectable in our samples due to the analytical method. However, we 
were able to show upregulated LysoPC in serum of IPF patients, indicating the crucial role of LysoPC-LPA pathway in IPF. Now, our findings need to be confirmed by different methods in a larger cohort of IPF patients including correlation to clinical parameters and disease severity.

\section{Conclusions}

In our study, we detected by global UHPLC-HRMS based metabolic profiling an increased serum level of a potential LysoPC and 3-hydroxydecanoyl carnitine in IPF patients compared to healthy controls. If confirmed in a larger cohort, the LysoPC might represent a potential marker for diagnostic and monitoring of IPF. The clinical meaning of this potential metabolite and its significance need to be evaluated in future studies. Global metabolic profiling by UHPLC-HRMS is a promising approach to detect possibly relevant pathophysiological pathways and potential serum biomarkers in IPF.

\section{Additional files}

\section{Additional file 1: Figure S1. Heat maps representing the $\log 10$ -}

transformed abundance profile (Pareto scaled) of the regulated metabolic features isolated by multivariate and/or univariate statistical analysis in the (top) pilot study and (bottom) validation study. Identity (summarized by the retention time followed by the corresponding $\mathrm{m} / \mathrm{z}$ ratio or neutral mass $n$ ) of the metabolic features are shown on the right side. Cells colored in red represent up-regulated, colored in blue down-regulated abundances. The analysis was done with the MetaboAnalyst online platform [59]. (PNG $581 \mathrm{~kb}$ )

Additional file 2: Figure S2. MS (top, $\mathrm{HDMS}^{\mathrm{E}}$ experiment) and MS/MS spectra (bottom, $\mathrm{HDMS}^{\mathrm{E}}$ experiment) of the metabolic features eluting at 5.9 min acquired in the positive ESI mode and potentially assigned to the $[\mathrm{M}+\mathrm{H}]^{+}$3-hydroxydecanoyl carnitine ion. The detection of the characteristic acylcarnitine fragment $\left[\mathrm{C}_{4} \mathrm{H}_{5} \mathrm{O}_{2}\right]^{+}$at $\mathrm{m} / \mathrm{z} 85.0284$ was confirmed by MS/MS spectra (bottom, HDMS ${ }^{\mathrm{E}}$ experiment). (PDF $\left.99 \mathrm{~kb}\right)$

Additional file 3: Figure S3. MS/MS spectra (DDA experiments) of the metabolic features eluting at 9.6 min acquired in the (a) positive and (b) negative ESI mode and potentially assigned to the $\left[\mathrm{M}+\mathrm{H}^{+}\right.$and $\left[\mathrm{M}+\mathrm{CHOO}^{-}\right.$ LysoPC ions, respectively. The main fragments are annotated with the corresponding structure, measured $\mathrm{m} / \mathrm{z}$ ratio and mass accuracy. (PDF $150 \mathrm{~kb}$ )

\section{Abbreviations \\ CCS: Collision cross section; DLCO: Diffusing capacity of the lung for carbon monoxide; ESI: Electrospray ionization; FDR: False discovery rate; FVC: Forced vital capacity; HDMSE: High definition mass spectrometry; HMDB: Human metabolome database; HRCT: High resolution computed tomography; HRMS: High-resolution mass spectromety; ILD: Interstitial lung disease; IPF: Idiopathic pulmonary fibrosis; LPA: Lysophosphatidic acid; LysoPC: Lysophosphatidylcholine; MS: Mass spectrometry; OPLS- DA: Orthogonal partial least squares discriminant analysis; PCA: Principal component analysis; TGF- $\beta$ : Transforming growth factor- $\beta$; TWIM: Traveling wave ion mobility; UHPLC: Ultra high-performance liquid chromatography; UIP: Usual interstitial pneumonia; VIP: Variable influence on projection}

\section{Acknowledgments}

UHPLC-HRMS analysis was performed at the Clinical Metabolomics Facility, Center of Laboratory Medicine from the Bern University Hospital (Inselspital Bern). We thank all the volunteers and patients for participation; Liselotte McEvoy, Susanne Krebser and Jeannette Frey for sample collection. The authors thank Christos Nakas and Anne Wehrhan for their support in statistical analysis.

\section{Funding}

The clinical trial NCT02173145 has been funded by the Swiss Lung Association, Berne (Lungenliga Schweiz). Set up of the Bernese IIP registry was initially financed with unrestricted grants from Intermune, Roche and Boehringer Ingelheim.

\section{Availability of data and materials}

Please contact author for data requests.

\section{Authors' contributions}

MF, CS and BR designed the study. BR, CS, CB and MF made substantial contributions to conception of the study and contributed to acquisition of data, analysis and interpretation of data. CS, CB and MF prepared the manuscript. TG contributed substantially by critical revision for important intellectual content; all authors have given final approval of the version to be published.

\section{Ethics approval and consent to participate}

The EBC samples from IPF patients have been obtained within the clinical trial NCT02173145 at baseline and from the IIP cohort study. Approval form the local ethical committee has been obtained previous to data acquisition (Swiss Ethics Committee, Bern, approval KEK 002/14 and 246/15 or PB_201601524) Consent for sample collection has been obtained. Data and material are available and stored in the IIP cohort study registry.

\section{Consent for publication}

Not applicable

\section{Competing interests}

MF has received travel support, advisory board and speaker fees as well as research funding from Boehringer Ingelheim, Roche and Intermune. TG has received advisory and speaker fees from $\mathrm{Bl}$ and Roche.

\section{Publisher's Note}

Springer Nature remains neutral with regard to jurisdictional claims in published maps and institutional affiliations.

\section{Author details}

'University Institute of Clinical Chemistry, Inselspital, Bern University Hospital, CH-3010 Bern, Switzerland. 'Department of Pulmonary Medicine, Inselspital, Bern University Hospital, University of Bern, Bern, Switzerland.

Received: 10 August 2017 Accepted: 2 January 2018

Published online: 10 January 2018

\section{References}

1. Raghu G, Collard HR, Egan JJ, Martinez FJ, Behr J, Brown KK, et al. An official ATS/ERS/JRS/ALAT statement: idiopathic pulmonary fibrosis: evidence-based guidelines for diagnosis and management. Am J Respir Crit Care Med. 2011; 183:788-824.

2. Ley B, Ryerson CJ, Vittinghoff E, Ryu JH, Tomassetti S, Lee JS, et al. A multidimensional index and staging system for idiopathic pulmonary fibrosis. Ann Intern Med. 2012;156:684-91.

3. Rudd RM, Prescott RJ, Chalmers JC, Johnston IDA. British Thoracic Society study on cryptogenic fibrosing alveolitis: response to treatment and survival. Thorax. 2007;62:62-6.

4. Funke M, Geiser T. Idiopathic pulmonary fibrosis: the turning point is now! Swiss Med Wkly. 2015;145:w14139.

5. Kim DS, Collard HR, King TE Jr. Classification and natural history of the idiopathic interstitial pneumonias. Proc Am Thorac Soc. 2006;3:285-92.

6. Coultas DB, Zumwalt RE, Black WC, Sobonya RE. The epidemiology of interstitial lung diseases. Am J Respir Crit Care Med. 1994;150:967-72.

7. Baumgartner K, Samet J, Stidley C, Colby T, Waldron J. Cigarette smoking: a risk factor for idiopathic pulmonary fibrosis. Am J Respir Crit Care. 1997;155: 242-8.

8. Geiser T. Idiopathic pulmonary fibrosis-a disorder of alveolar wound repair? Swiss Med Wkly. 2003;133:405-11.

9. Barkauskas CE, Noble PW. Cellular mechanisms of tissue fibrosis. 7. New insights into the cellular mechanisms of pulmonary fibrosis. Am J Physiol Cell Physiol. 2014;306:C987-96. 
10. Ahluwalia N, Shea BS, Tager AM. New therapeutic targets in idiopathic pulmonary fibrosis. Aiming to rein in runaway wound-healing responses. Am J Respir Crit Care Med. 2014;190:867-78.

11. Raghu G, Rochwerg B, Zhang Y, Garcia CAC, Azuma A, Behr J, et al. An official ATS/ERS/JRS/ALAT clinical practice guideline: treatment of idiopathic pulmonary fibrosis. An update of the 2011 clinical practice guideline. Am J Respir Crit Care Med. 2015;192:e3-19.

12. Ley B, Brown KK, Collard HR. Molecular biomarkers in idiopathic pulmonary fibrosis. Am J Physiol Lung Cell Mol Physiol. 2014;307:L681-91.

13. Bujak R, Struck-Lewicka W, Markuszewski MJ, Kaliszan R. Metabolomics for laboratory diagnostics. J Pharm Biomed Anal. 2015;113:108-20.

14. Reinke SN, Gallart-Ayala H, Gómez C, Checa A, Fauland A, Naz S, et al. Metabolomics analysis identifies different metabotypes of asthma severity. Eur Respir J. 2017;49:1601740.

15. Guiot J, Moermans C, Henket M, Corhay J-L, Louis R. Blood biomarkers in idiopathic pulmonary fibrosis. Lung. 2017;195:273-80.

16. Paglia G, Angel P, Williams JP, Richardson K, Olivos HJ, Thompson JW, et al. Ion mobility-derived collision cross section as an additional measure for lipid fingerprinting and identification. Anal Chem. 2015;87:1137-44.

17. Benjamini $Y$, Hochberg $Y$. Controlling the false discovery rate: a practical and powerful approach to multiple testing. J R Stat Soc B. 1995;57:289-300.

18. Bally L, Bovet C, Nakas CT, Zueger T, Prost J-C, Nuoffer J-M, et al. A metabolomics approach to uncover effects of different exercise modalities in type 1 diabetes. Metabolomics. 2017;13:78.

19. Hines KM, May JC, McLean JA, Xu L. Evaluation of collision cross section Calibrants for structural analysis of lipids by traveling wave ion mobilitymass spectrometry. Anal Chem. 2016;88:7329-36.

20. Godzien J, Ciborowski M, Martínez-Alcázar MP, Samczuk P, Kretowski A, Barbas C. Rapid and reliable identification of phospholipids for untargeted Metabolomics with LC-ESI-QTOF-MS/MS. J Proteome Res. 2015;14:3204-16.

21. Yung YC, Stoddard NC, Chun J. LPA receptor signaling: pharmacology, physiology, and pathophysiology. J Lipid Res. 2014;55:1192-214.

22. Naz S, Kolmert J, Yang M, Reinke SN, Kamleh MA, Snowden S, et al. Metabolomics analysis identifies sex-associated metabotypes of oxidative stress and the autotaxin-lysoPA axis in COPD. Eur Respir J. 2017:49:1602322.

23. Zhao YD, Yin L, Archer S, Lu C, de Perrot M. Metabolic heterogeneity of idiopathic pulmonary fibrosis: a metabolomic study. BMJ Open Respir Res. 2017;4:e000183.

24. Kang YP, Lee SB, Lee JM, Kim HM, Hong JY, Lee WJ, et al. Metabolic profiling regarding pathogenesis of idiopathic pulmonary fibrosis. J Proteome Res. 2016;15:1717-24.

25. Luo F, Le N-B, Mills T, Chen N-Y, Karmouty-Quintana H, Molina JG, et al. Extracellular adenosine levels are associated with the progression and exacerbation of pulmonary fibrosis. FASEB J. 2016;30:874-83.

26. Zhou Y, Murthy JN, Zeng D, Belardinelli L, Blackburn MR. Alterations in adenosine metabolism and signaling in patients with chronic obstructive pulmonary disease and idiopathic pulmonary fibrosis. PLoS One. 2010;5:e9224.

27. Ferrari D, Gambari R, Idzko M, Müller T, Albanesi C, Pastore S, et al. Purinergic signaling in scarring. FASEB J. 2016;30:3-12.

28. Vasudha KC, Kumar AN, Venkatesh T. Studies on the age dependent changes in serum adenosine deaminase activity and its changes in hepatitis. Indian J Clin Biochem. 2006:21:116-20.

29. Baker DL, Umstot ES, Desiderio DM, Tigyi GJ. Quantitative analysis of Lysophosphatidic acid in human blood fractions. Ann N Y Acad Sci. 2006; 905:267-9.

30. Alsafadi HN, Staab-Weijnitz CA, Lehmann M, Lindner M, Peschel B, Königshoff $M$, et al. An ex vivo model to induce early fibrosis-like changes in human precision-cut lung slices. Am J Physiol - Lung Cell Mol Physiol. 2017;312:L896-902.

31. Mendoza FA, Mansoor M, Jimenez SA. Treatment of rapidly progressive systemic sclerosis: current and futures perspectives. Expert Opin orphan drugs. 2016:4:31-47

32. Murph M, Tanaka T, Pang J, Felix E, Liu S, Trost R, et al. Liquid chromatography mass spectrometry for quantifying plasma Lysophospholipids: potential biomarkers for cancer diagnosis: Methods in Enzymology; 2007. p. 1-25.

33. Knowlden S, Georas SN. The Autotaxin-LPA Axis emerges as a novel regulator of lymphocyte homing and inflammation. J Immunol. 2014;192:851-7.

34. Navab M, Chattopadhyay A, Hough G, Meriwether D, Fogelman SI, Wagner $A C$, et al. Source and role of intestinally derived lysophosphatidic acid in dyslipidemia and atherosclerosis. J Lipid Res. 2015;56:871-87.
35. del Bas JM, Caimari A, Rodriguez-Naranjo MI, Childs CE, Paras Chavez C, West AL, et al. Impairment of lysophospholipid metabolism in obesity: altered plasma profile and desensitization to the modulatory properties of n-3 polyunsaturated fatty acids in a randomized controlled trial. Am J Clin Nutr. 2016;104:266-79.

36. Ackerman SJ, Park GY, Christman JW, Nyenhuis S, Berdyshev E, Natarajan V. Polyunsaturated lysophosphatidic acid as a potential asthma biomarker. Biomark Med. 2016;10:123-35.

37. Balood M, Zahednasab H, Siroos B, Mesbah-Namin SA, Torbati S, Harirchian $\mathrm{MH}$. Elevated serum levels of lysophosphatidic acid in patients with multiple sclerosis. Hum Immunol. 2014:75:411-3.

38. Velasco M, O'Sullivan C, Sheridan GK. Lysophosphatidic acid receptors (LPARs): potential targets for the treatment of neuropathic pain. Neuropharmacology. 2017;113:608-17.

39. Brunnert D, Sztachelska M, Bornkessel F, Treder N, Wolczynski S, Goyal P, et al. Lysophosphatidic acid and sphingosine 1-phosphate metabolic pathways and their receptors are differentially regulated during decidualization of human endometrial stromal cells. Mol Hum Reprod. 2014 20:1016-25.

40. Sakai N, Chun J, Duffield JS, Lagares D, Wada T, Luster AD, et al. Lysophosphatidic acid signaling through its receptor initiates profibrotic epithelial cell fibroblast communication mediated by epithelial cell derived connective tissue growth factor. Kidney Int. 2017;91:628-41.

41. Kaffe E, Katsifa A, Xylourgidis N, Ninou I, Zannikou M, Harokopos V, et al. Hepatocyte autotaxin expression promotes liver fibrosis and cancer Hepatology. 2017;65:1369-83.

42. Tager AM, LaCamera P, Shea BS, Campanella GS, Selman M, Zhao Z, et al. The lysophosphatidic acid receptor LPA1 links pulmonary fibrosis to lung injury by mediating fibroblast recruitment and vascular leak. Nat Med. 2008;14:45-54.

43. Tager AM. Autotaxin emerges as a therapeutic target for idiopathic pulmonary fibrosis: limiting fibrosis by limiting lysophosphatidic acid synthesis. Am J Respir Cell Mol Biol. 2012;47:563-5.

44. Oikonomou N, Mouratis M-A, Tzouvelekis A, Kaffe E, Valavanis C, Vilaras G, et al. Pulmonary Autotaxin expression contributes to the pathogenesis of pulmonary fibrosis. Am J Respir Cell Mol Biol. 2012;47:566-74.

45. Xu MY, Porte J, Knox AJ, Weinreb PH, Maher TM, Violette SM, et al. Lysophosphatidic acid induces alphavbeta6 integrin-mediated TGF-beta activation via the LPA2 receptor and the small G protein $G$ alpha (q). Am J Pathol. 2009;174:1264-79.

46. Huang LS, Fu P, Patel P, Harijith A, Sun T, Zhao Y, et al. Lysophosphatidic acid receptor-2 deficiency confers protection against bleomycin-induced lung injury and fibrosis in mice. Am J Respir Cell Mol Biol. 2013;49:912-22.

47. Tanaka M, Okudaira S, Kishi Y, Ohkawa R, Iseki S, Ota M, et al. Autotaxin stabilizes blood vessels and is required for embryonic vasculature by producing Lysophosphatidic acid. J Biol Chem. 2006;281:25822-30.

48. Tokumura A, Majima E, Kariya Y, Tominaga K, Kogure K, Yasuda K, et al. Identification of human plasma lysophospholipase D, a lysophosphatidic acid-producing enzyme, as autotaxin, a multifunctional phosphodiesterase. Jiol Chem. 2002;277:39436-42.

49. Lin M-E, Herr DR, Chun J. Lysophosphatidic acid (LPA) receptors: signaling properties and disease relevance. Prostaglandins Other Lipid Mediat. 2010; 91:130-8.

50. Fisher $A B$, Dodia $C$. Role of phospholipase $A 2$ enzymes in degradation of dipalmitoylphosphatidylcholine by granular pneumocytes. J Lipid Res. 1996; 37:1057-64.

51. Funke M, Zhao Z, Xu Y, Chun J, Tager AM. The lysophosphatidic acid receptor LPA1 promotes epithelial cell apoptosis after lung injury. Am J Respir Cell Mol Biol. 2012;46:355-64

52. Van Meeteren LA, Moolenaar WH. Regulation and biological activities of the autotaxin-LPA axis. Prog Lipid Res. 2007:46:145-60.

53. Ntolios P, Papanas N, Nena E, Boglou P, Koulelidis A, Tzouvelekis A, et al. Mean platelet volume as a surrogate marker for platelet activation in patients with idiopathic pulmonary fibrosis. Clin Appl Thromb. 2016; 22:346-50.

54. Montesi SB, Mathai SK, Brenner LN, Gorshkova IA, Berdyshev EV, Tager AM, et al. Docosatetraenoyl LPA is elevated in exhaled breath condensate in idiopathic pulmonary fibrosis. BMC Pulm Med. 2014;14:5

55. >Nowak-Machen M, Lange M, Exley M, Wu S, Usheva A, Robson SC. Lysophosphatidic acid generation by pulmonary NKT cell ENPP-2/ autotaxin exacerbates hyperoxic lung injury. Purinergic Signal. 2015;11: 455-61. 
56. Park GY, Lee YG, Berdyshev E, Nyenhuis S, Du J, Fu P, et al. Autotaxin production of lysophosphatidic acid mediates allergic asthmatic inflammation. Am J Respir Crit Care Med. 2013;188:928-40.

57. Study to Assess Safety, Tolerability, Pharmacokinetic and Pharmacodynamic Properties of GLPG1690 - ClinicalTrials.gov. https:/clinicaltrials.gov/ct2/ show/NCT02738801?term=GLPG1690\&rank=2. Accessed 29 Nov 2017.

58. Desroy N, Housseman C, Bock X, Joncour A, Bienvenu N, Cherel L, et al. Discovery of 2-[[2-Ethyl-6-[4-[2-(3-hydroxyazetidin-1-yl)-2-oxoethyl] piperazin1-yl]-8-methylimidazo [1,2-a] pyridin-3-yl] methylamino]-4-(4-fluorophenyl) thiazole-5-carbonitrile (GLPG1690), a first-in-class Autotaxin inhibitor undergoing clinical evaluation. J Med Chem. 2017;60:3580-90.

59. Xia J, Wishart DS, Xia J, Wishart DS. Using MetaboAnalyst 3.0 for comprehensive Metabolomics data analysis. In: Current protocols in bioinformatics. Hoboken: Wiley Inc; 2016. p. 14.10.1-14.10.91.

60. Rindlisbacher B, Strebel C, Guler S, Kollár A, Geiser T, Martin Fiedler G, et al. Exhaled breath condensate as a potential biomarker tool for idiopathic pulmonary fibrosis—a pilot study. J Breath Res. 2017;12:16003.

Submit your next manuscript to BioMed Central and we will help you at every step:

- We accept pre-submission inquiries

- Our selector tool helps you to find the most relevant journal

- We provide round the clock customer support

- Convenient online submission

- Thorough peer review

- Inclusion in PubMed and all major indexing services

- Maximum visibility for your research

Submit your manuscript at www.biomedcentral.com/submit
Biomed Central 